\title{
A Elbphilharmonie em discussão: vozes críticas desde Hamburgo Um breve insight sobre o atual debate local
}

\author{
Judith Bopp, M.A.*
}

Universität zu Köln, Geographisches Institut, Albertus-MagnusPlatz, 50923 Köln, judithbopp@web.de

\section{Kaya Alice de Wolff **}

Leuphana Universität Lüneburg, Fakultät Kulturwissenschaften, Scharnhorststraße 1, 21335 Lüneburg, +49 (0) 4131-677-2572, kayadewolff@gmx.de

\section{Tradução:}

\section{Caboverde Design Digital Ltda/American Journal Experts (AJE)}

Tradução técnica e revisão:

\section{Francisco Sales Trajano Filho}

Arquiteto, professor doutor do Instituto de Arquitetura e Urbanismo da Universidade de São Paulo, Avenida Trabalhador Sancarlense, 400, CEP 13.566-590, São Carlos, SP, (16) 33739294, sales@sc.usp.br

\footnotetext{
* Judith Bopp é estudante de doutorado no Instituto de Geografia da Universität Köln.

** Kaya Alice de Wolff é mestranda de ciências culturais na Leuphana Universität Lüneburg, residente de Hamburgo. Em 2011, estudou durante um semestre na IAU, USP de São Carlos, como parte do UNIBRAL - Programa de Intercâmbio, organizado pela CAPES e DAAD.
}

Elbphilharmonie deveria se tornar o ponto alto, o coroamento do projeto em larga escala da HafenCity, de Hamburgo, destinado a estabelecer um novo marco cultural e transformar a "cidade hanseática" na "cidade da música" de reputação internacional. Contudo, ainda no início de 2012, a espetacular filarmônica permanece muito mais como uma projeção futura do que uma realidade arquitetônica, com o projeto sendo discutido localmente menos como "projeto farol" e mais como "criançaproblema".

Hamburgo, Alemanha. A cidade hanseática com seus 1,8 milhão de habitantes (cerca de 4,3 milhões em toda a área metropolitana) é, atualmente, a terceira maior cidade do país - até então amplamente conhecida por seu porto, o Reeperbahn, seu time de futebol FC St. Pauli, e seus numerosos eventos musicais.

Antes de tudo, Hamburgo é o "portal da Alemanha para o mundo". Instalado em uma posição geográfica privilegiada, o porto interno de containers detém uma importância econômica internacional e está em desenvolvimento contínuo. A cidade multicultural oferece uma ampla variedade de estabelecimentos de cultura e lazer. Como a maioria das cidades alemãs, Hamburgo está afundada em dívidas e particularmente seu orçamento doméstico para cultura e educação sofre com cortes contínuos de fundos pelas autoridades públicas. A despeito disso, o financiamento privado tem uma forte tradição, e milionários e fundações locais costumam ser atraídos para o patrocínio de projetos de prestígio. O melhor exemplo é a Elbphilharmonie, ambicioso coroamento do projeto da HafenCity, iniciado em 1997.

O lema de Hamburgo é aquele da "cidade em crescimento". No curso dessa política de desenvolvimento urbano, a nova HafenCity, na antiga área portuária ao sul da Speicherstadt, tombada como patrimônio, estende a superfície da cidade em cerca de 40\%. HafenCityé, atualmente, o maior projeto de desenvolvimento de área central da Europa. A extensão urbana será utilizada para fins comerciais, residenciais, educacionais, de lazer e abastecimento, sendo conduzida segundo o objetivo do governo municipal de possibilitar que Hamburgo possa competir internacionalmente por empreendimentos, visitantes e habitantes, com base no slogan "urbana e marítima". 


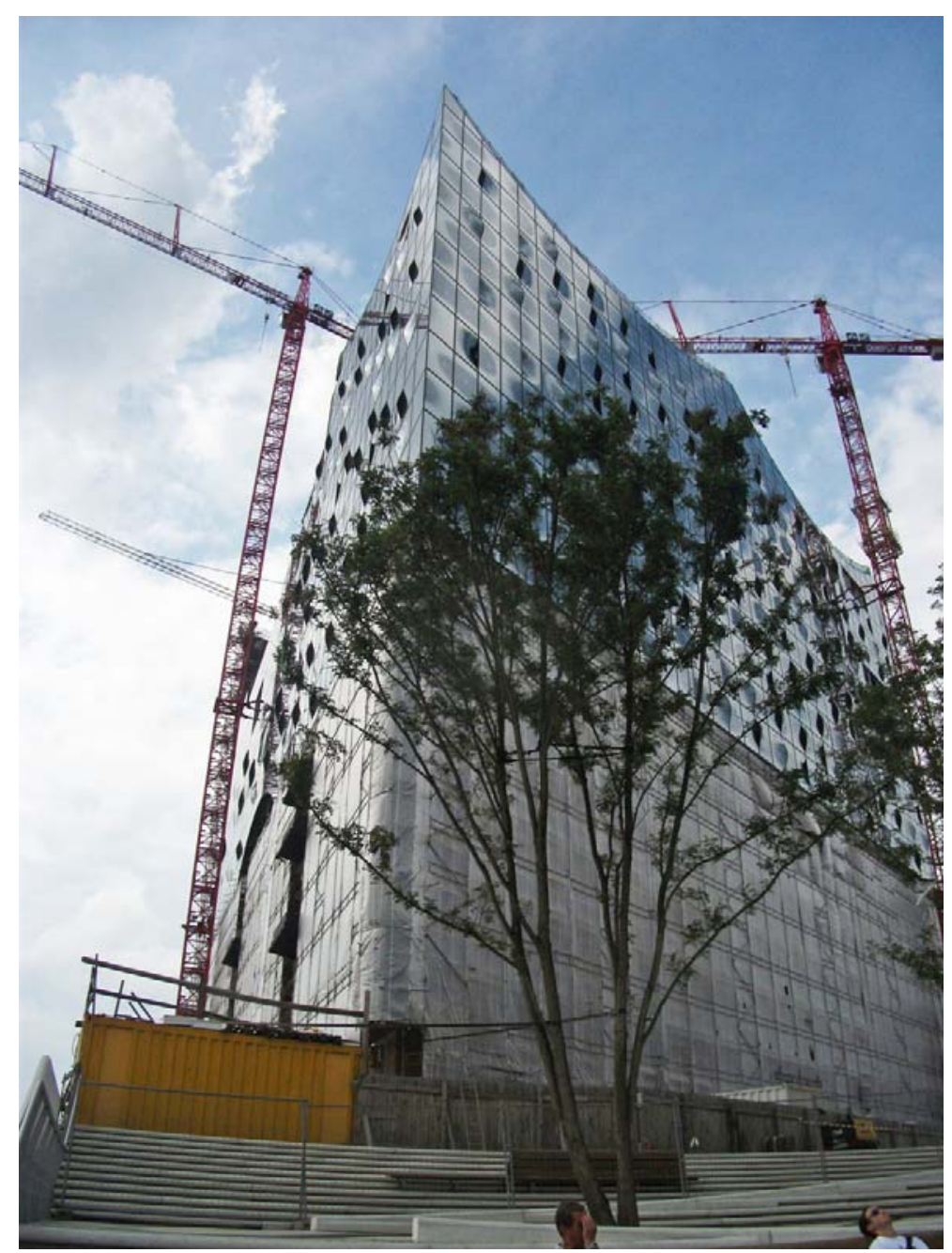

Figuras 1 e 2: Elbphilharmonie. Fonte: autoras.

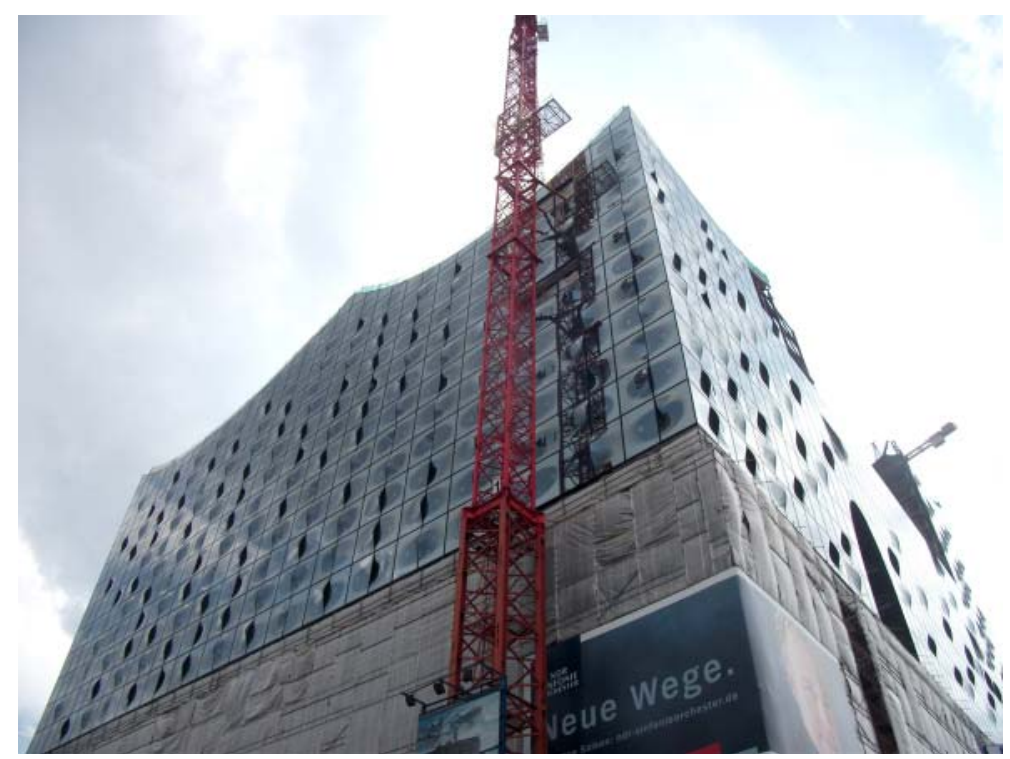


A revitalização do seu waterfront e o crescente número de eventos festivos são processos típicos das intervenções em cidades portuárias ocorridos recentemente mundo afora, como, por exemplo, em Sydney, Amsterdam, Nova York, Barcelona. A expressão "HafenCity", "cidade portuária" manifesta as aspirações internacionais do projeto de Hamburgo.

Como maior destaque do projeto da HafenCity, a cidade pretendia estabelecer um novo marco cultural, a Elbphilharmonie, conformando um novo skyline urbano e transformando a cidade hanseática em uma "Cidade da Música" internacional. "A Elbphilharmonie serve não só como um farol de boas-vindas para a nova HafenCity, mas também para Hamburgo como Cidade da Música" , informa o site oficial do projeto.

Hamburgo, de fato, atrai turistas de todo o mundo principalmente em razão de sua reputação internacional de cidade musical A excelência musical de alta cultura, entretanto, permanece ainda como um nicho.

Quando o empreendedor de Hamburgo Alexander Gérard apresentou a Elbphilharmonie em 2003, o governo municipal até então hesitante, assim como os cidadãos de Hamburgo, ficaram eufóricos, fisgados pela ideia de criar um novo emblema cultural espetacular na dimensão da Torre Eiffel de Paris ou da Ópera de Sydney. Declarações confiantes dos arquitetos Herzog \& De Meuron acentuavam os efeitos psicológicos de seu projeto: "Os cidadãos de Hamburgo buscam uma nova interface entre a cidade e o porto, que definirá a cidade culturalmente. A Elbphilharmonie oferece exatamente isso".

Espera-se que a nova filarmônica torne-se um complexo multifuncional, uma "obra de arte total, uma experiência excepcional de arquitetura e música em proximidade direta com a água". Além dos dois auditórios, o prédio conta com área de estacionamento, um hotel, 45 apartamentos residenciais e uma plataforma panorâmica de $37 \mathrm{~m}$ de altura. Representantes do star-system arquitetônico, Herzog \& de Meuron realizaram nos últimos anos vários projetos espetaculares de reconhecimento internacional, como a Tate Gallery, de Londres, a Allianz-Arena de Munique e o Estádio Nacional de
Pequim para os Jogos Olímpico de 2008. O projeto da Elbphilharmonie de Hamburgo busca agora completar essa ambiciosa série.

A enorme construção de vidro almeja incorporar a arquitetura contemporânea ao perfil histórico do porto. Uma gigantesca estrutura de vidro curvado em forma de onda ergue-se do topo da fachada de um antigo armazém de cacau: gigantesca ao menos nas animações do projeto: o resultado final do impressionante telhado em forma de onda deve ser mais modesto. Como o hotel consumiu mais espaço que o planejado inicialmente, o edifício teve sua altura aumentada em um dos lados. Por isso, os "enormes desfiladeiros agitados de ondas", que deveriam ser a mais impressionante característica do prédio, tiveram que ser relativamente achatados e, como resultado, parecerão "menos enormes" e "menos agitados".

Fato é que a euforia inicial deu passagem à frustração para grande parte da população local. Em especial, por conta dos imensos custos adicionais e dos recorrentes erros de cálculo durante o processo de construção, a Elbphilharmonie tornou-se objeto de controvérsia pública. A parcela dos custos da cidade de Hamburgo foi aumentada dos originalmente planejados 77 milhões para 325 milhões de euros. Inicialmente planejada para 2009, a conclusão foi adiada, mais uma vez, na virada do ano: oficialmente, a conclusão agora está prevista para novembro de 2014; extraoficialmente, o ano de 2015 já está em discussão.

O resultado são cidadãos frustrados e um "diretor sem casa" desesperado. Diferente da situação de outras instituições culturais alemãs, Christoph Lieben-Seutter, indicado como diretor artístico da Elbphilharmonie, não está lutando contra o fechamento de sua casa, mas pela sua abertura. Ele mesmo tem dúvidas quanto à conclusão do auditório em 2014. Provavelmente não terá a chance de inaugurar seu palco antes do término de seu contrato expirar em julho de 2015.

Face às contínuas críticas e frustrações os arquitetos Herzog \& de Mouron relembram a dedicação e o entusiasmo inicial pelo projeto em Hamburgo: “[...] com relação à Elbphilharmonie, é psicologicamente interessante que o projeto tenha começado como uma ideia que foi levada adiante a partir do povo, 

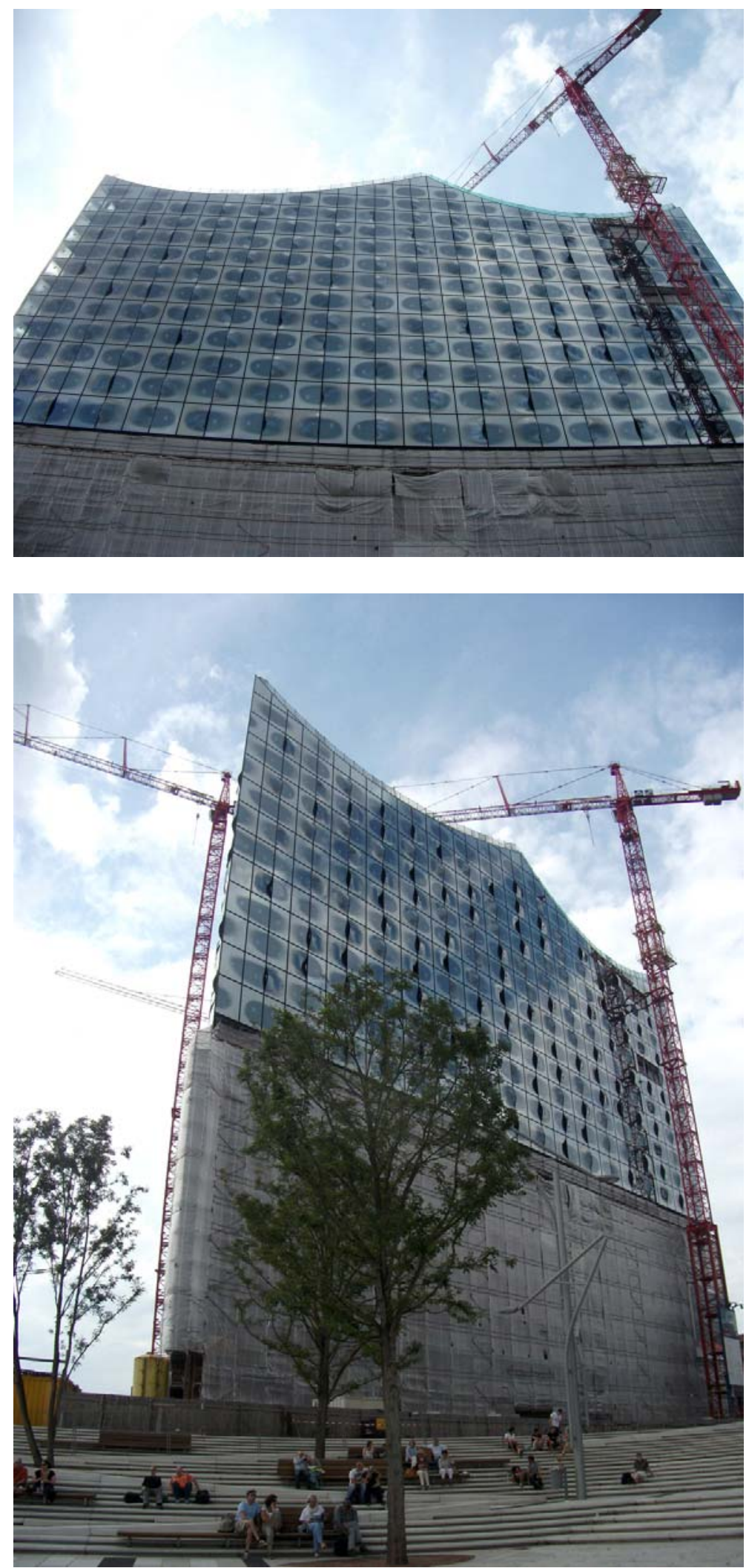

Figuras 3 e 4: Elbphilharmonie. Fonte: autoras. 
Figuras 5 e 6: Elbphilharmonie. Fonte: autoras. e não imposta de cima para baixo. Às vezes, é fácil se esquecer disso ao ler as críticas na imprensa. Mas as primeiras imagens do projeto impressionaram as pessoas de tal forma que o público e a mídia exerceram uma pressão enorme sobre políticos e investidores para realizarem este projeto".

Ao final, com suas escapadas a la diva, a Elbphilharmonie certamente garantirá seu trono na confederação internacional de arquitetura contemporânea. Nesse sentido, vale olhar para o passado, para os debates sobre a Opera House de Sydney, em 1973. A construção da ópera levou três vezes mais tempo do que originalmente planejado, e custou 14 vezes mais do que estimado inicialmente. Naquela época, ao ser confrontado por críticas públicas semelhantes, o arquiteto Jörn Utzon argumentou, de maneira autoconfiante: "Custos e tempo de construção? Quem questionaria a Catedral de Chartres sobre isso hoje em dia? Levou mais de cem anos para ser construída".

\section{Fontes principais}

www.hafencity.com/en/home.html www.elbphilharmonie-erleben.de/en/ www.herzogdemeuron.com
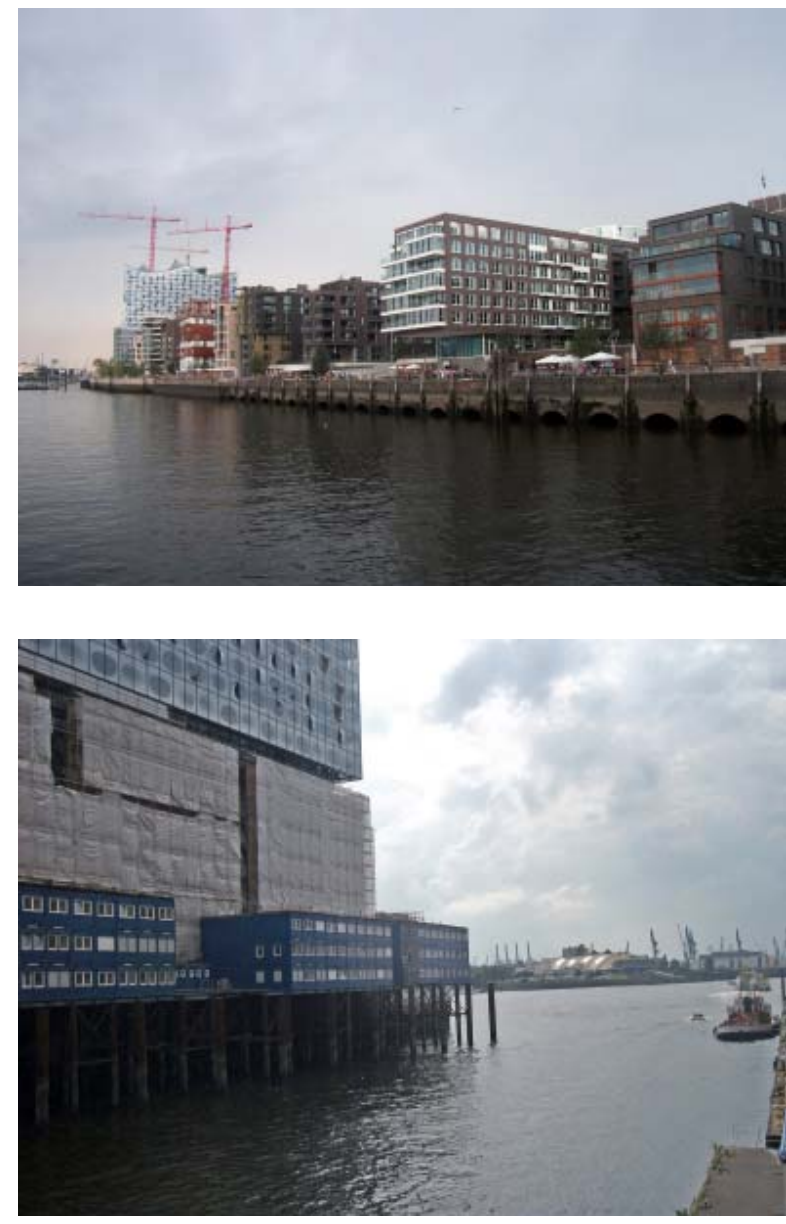

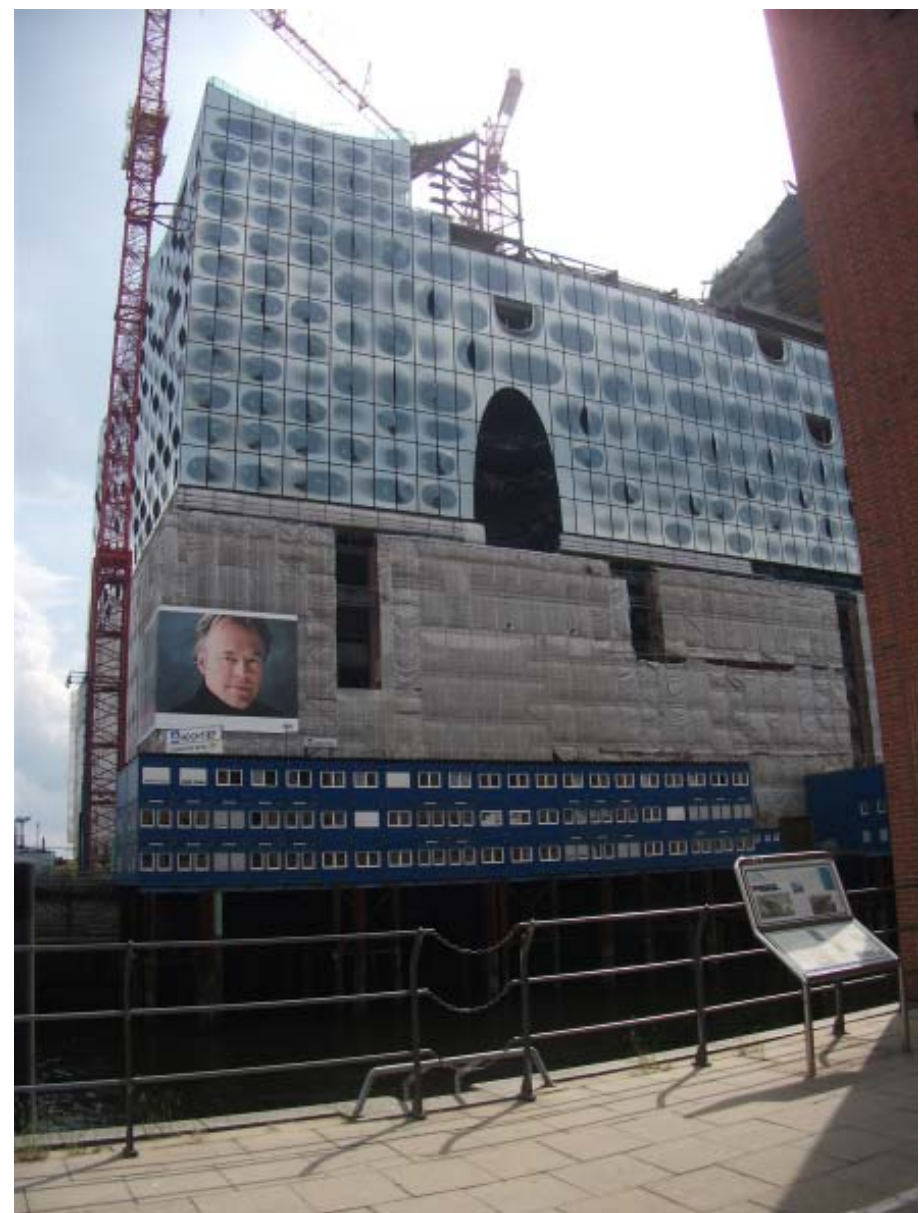

